\title{
Asymmetric Seafloor Spreading of the Southern Mariana Trough Back-Arc Basin
}

\author{
Nobukazu Seama and Kyoko Okino
}

\begin{abstract}
We compiled multi-narrow beam bathymetric data and geomagnetic field data obtained by a series of JAMSTEC research cruises in the Southern Mariana Trough back-arc basin, where is selected as one of three integrated target sites for the Japanese TAIGA Project. The bathymetric data are used to trace the non-transform offsets that define the ridge segments at the offaxis, and to characterize the seafloor morphology signatures from the bathymetry profiles across the spreading axes of two ridge segments. The geomagnetic field data are used to derive the crustal magnetization distribution and to estimate the spreading rate of the southern segment. Both of the spreading rate and the seafloor deepening rate of the southern segment support highly asymmetric seafloor spreading; much faster spreading in the west side of the spreading axis compared to the east side (trench side). We estimated the full spreading rate as $46 \mathrm{~km} / \mathrm{Myr}$ with its half rate of $33 \mathrm{~km} / \mathrm{Myr}$ for the west side and $13 \mathrm{~km} / \mathrm{Myr}$ for the east side. In contrast to the southern segment, our results indicate that the northern segment has a different style of the asymmetric seafloor spreading; that is accompanied by an obvious trace of a ridge jump to the trench side. The local symmetry axis in the bathymetry profiles locates at a distance of $18 \mathrm{~km}$ to the west from the spreading axis, suggesting that it is the failed spreading axis due to the ridge jump. The location of this failed spreading axis coincides with the center of the bull's eye feature in the Mantle Bouguer anomaly, suggesting that the ridge jump to the trench side with an increase in the magma supply. We propose that the influence of the low viscosity region in the mantle wedge due to hydration driven by water release from the subducting slab leads to the highly asymmetric seafloor spreading; the low viscosity mantle would preferentially captures the mantle upwelling zone beneath the spreading axis as the spreading axis has been kept in the area closed to the low viscosity region in the mantle wedge, resulting in the highly asymmetric seafloor spreading. Further, the different styles of the asymmetric seafloor spreading between the northern segment and the southern segment probably show evidence that the influence varies with the distance from the low viscosity region in the mantle wedge.
\end{abstract}

\section{Keywords}

Asymmetric seafloor spreading • Back-arc basin • Bathymetry • Geomagnetic anomaly field $\bullet$ Mantle Bouguer anomaly $\bullet$ Ridge jump

N. Seama $(\bowtie)$

Department of Earth and Planetary Sciences,

Kobe University, 1-1 Rokkodai, Nada, Kobe 657-8501, Japan

e-mail: seama@kobe-u.ac.jp

\section{K. Okino}

Atmosphere and Ocean Research Institute, The University of Tokyo,

5-1-5 Kashiwanoha, Kashiwa, Chiba 277-8564, Japan

\subsection{Introduction}

The Mariana Trough is a current active back-arc basin with crescent-shaped (Fig. 20.1). Repeated GPS surveys in the Mariana Islands show that the present spreading rates of the 

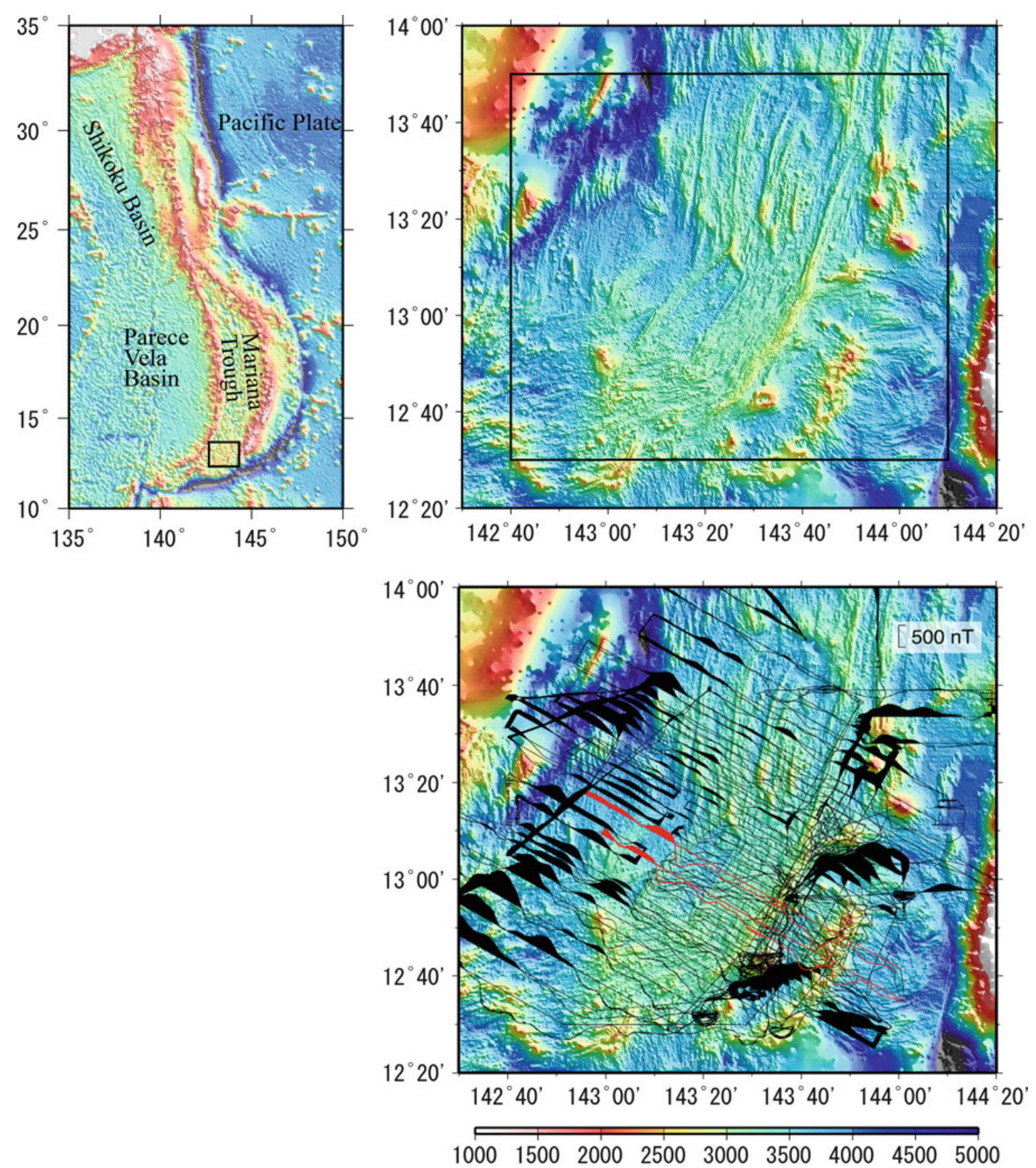

Fig. 20.1 Bathymetry map of the Southern Mariana Trough (top right) and its location shown by the box in the regional map (top left). The box in the bathymetry map indicates the location for Figs. 20.2 and 20.3. Profiles of the geomagnetic anomaly field along the ship's track

Mariana Trough back-arc basin increase from the north to the south; the full spreading rates are $15.9 \pm 6.6 \mathrm{~km} / \mathrm{Myr}$ at $18.7^{\circ} \mathrm{N}$ and $44.6 \pm 2.7 \mathrm{~km} / \mathrm{Myr}$ at $13.6^{\circ} \mathrm{N}$ with its Euler pole position being to the south of the junction of the Mariana Arc and the West Mariana Ridge located near $23^{\circ} \mathrm{N}$ (Kato et al. 2003). The studies of the geomagnetic anomalies using the Matuyama-Brunhes boundary $(0.78 \mathrm{Ma})$ reported the similarity in the spreading trend; the full spreading rates are (bottom). Positive values are shaded. The profiles shown by red color are used for a forward modeling to examine the isochrones identifications of the southern segment as shown in Fig. 20.4

$10 \mathrm{~km} / \mathrm{Myr}$ at $22^{\circ} \mathrm{N}$ in the northern end (Yamazaki et al. 2003 ) and $\sim 64 \mathrm{~km} / \mathrm{Myr}$ in maximum at $13^{\circ} \mathrm{N}$ in the southern end (Martinez et al. 2000). These two different methods show that the full spreading rate of the Southern Mariana Trough back-arc basin ranges $45-64 \mathrm{~km} / \mathrm{Myr}$.

The Southern Mariana Trough back-arc basin (Fig. 20.1) has fast spreading morphologic and geophysical characteristics that are unlike the features of the basin to 
Fig. 20.2 Present spreading axis (solid lines), failed spreading axis (thick broken lines), and nontransform offset traces determined from seafloor morphology (thin broken lines) shown in the bathymetry map (top), the Mantle Bouguer anomaly map (middle), and the distribution of the crustal magnetization derived from the total geomagnetic anomaly field data (bottom). The arrow in the middle figure shows the bull's eye feature, in the center of which the failed spreading axis locates. In the bottom figure, our identifications of the geomagnetic anomaly lineations (green lines with its geomagnetic anomaly number) and bathymetry contours of 3,000 $\mathrm{m}$ depth (dots) are also shown
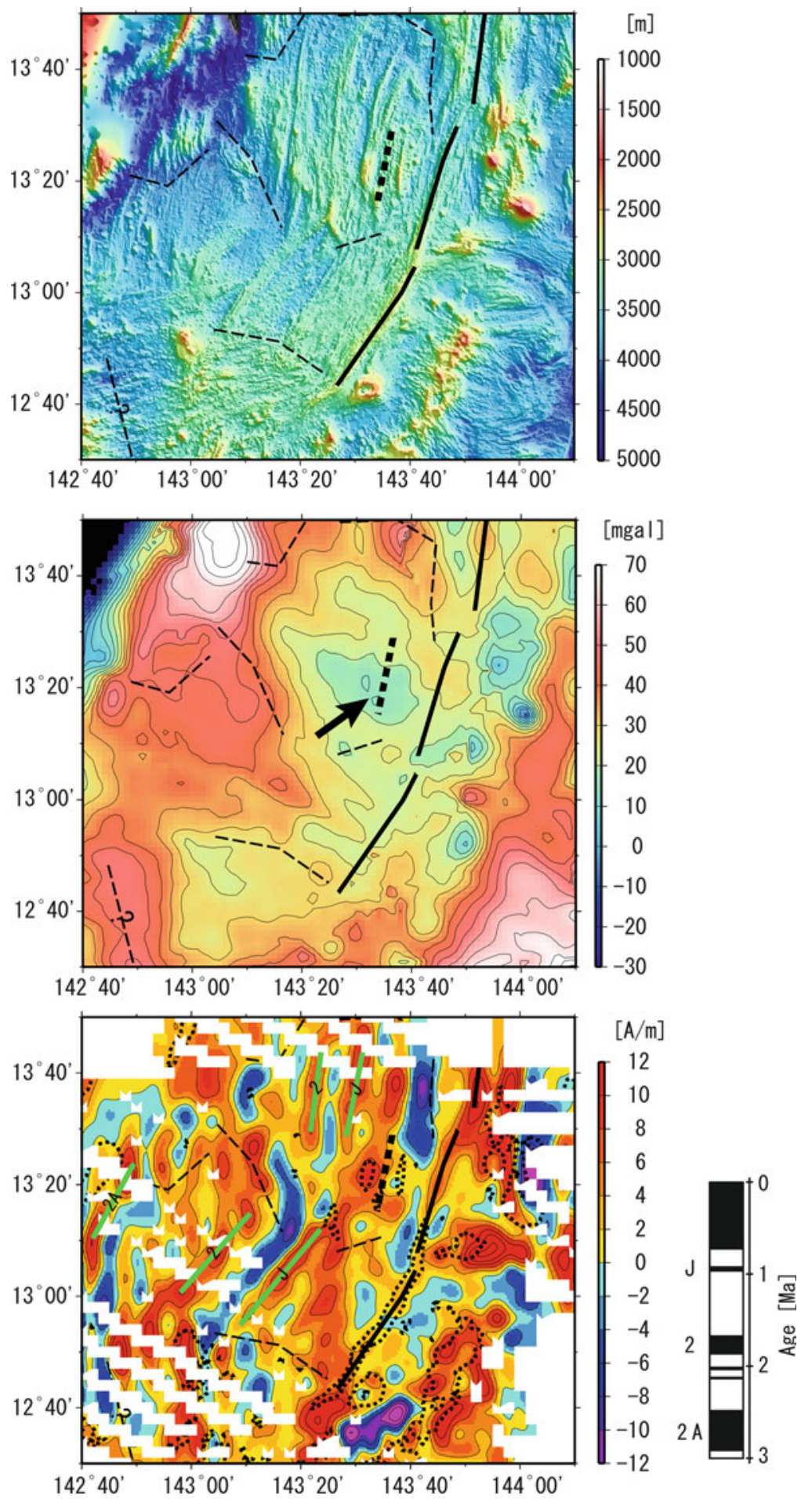

the north (Martinez et al. 2000), despite the full spreading rate of $45-64 \mathrm{~km} / \mathrm{Myr}$ being categorized as slow spreading. The morphology of the spreading axis shows an axial relief with a broad, smooth cross section, and lacks a deep central graben (Martinez et al. 2000). The crustal thickness variation along the spreading axis that was estimated using the Mantle Bouguer anomalies shows higher individual crustal thickness averages $(5.9-6.9 \mathrm{~km})$ and smaller normalized variations in crustal thickness $(28-30 \mathrm{~m} / \mathrm{km})$, suggesting a sheetlike mantle upwelling with a relatively higher magmatic activity beneath the ridge segments (Kitada et al. 2006). Further, the seismic reflection data show a possible magma chamber reflector beneath the spreading axis (Becker et al. 2010). All these morphologic and geophysical 


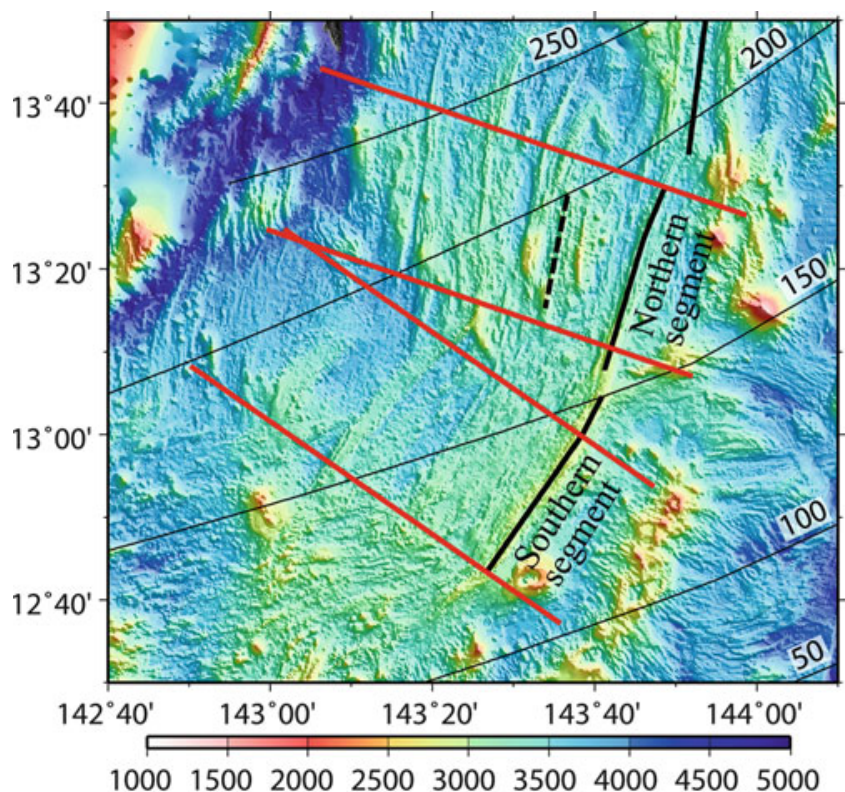

Fig. 20.3 Bathymetry profiles across the spreading axes of the northern segment (right top) and the southern segment (right bottom). Each bathymetry profile is located between the two red lines of each segment in the left figure, and it is taken parallel to the red lines with interval of $1 \mathrm{~km}$. The distance is shown from the spreading axis and the positive value is to the east. The arrow in the northern segment bathymetry profiles shows the symmetry axis of the bathymetry profiles. This symmetry is local within a distance of $10 \mathrm{~km}$ with respect to the symmetry axis, but this local symmetry axis is similar in the bathymetric feature to a spreading axis, suggesting that it is the

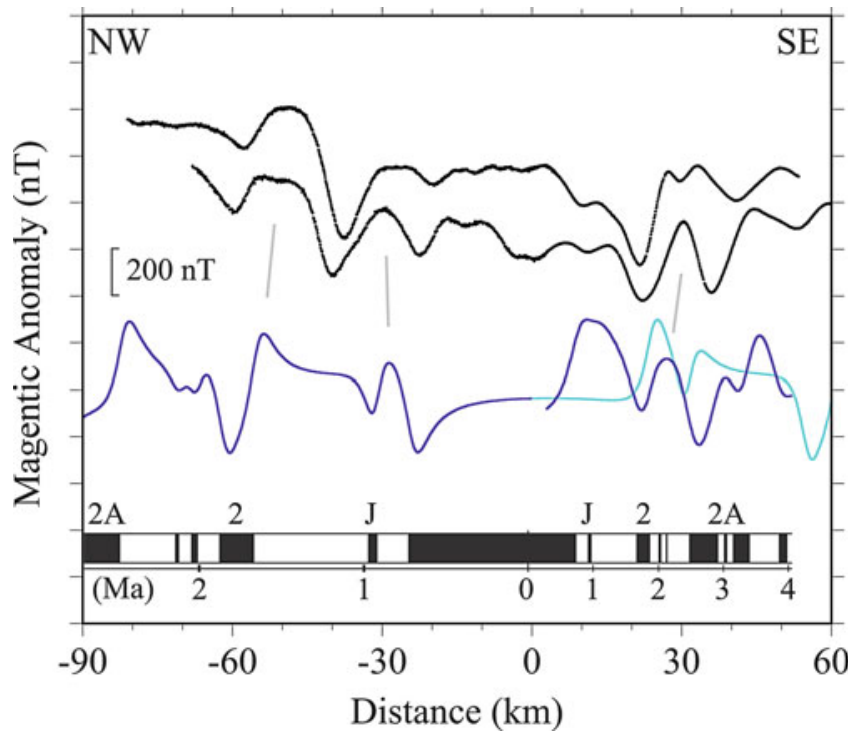

Fig. 20.4 Comparison between observed and calculated geomagnetic anomaly field profiles across the spreading axis of the southern segment. The location of the observed geomagnetic anomaly field profiles (black) are shown by red color in Fig. 20.1. The calculated geomagnetic anomaly field profiles are based on a forward modeling with its half spreading rates of $33 \mathrm{~km} / \mathrm{Myr}$ for the west side (blue), $13 \mathrm{~km} / \mathrm{Myr}$ for the east side (blue), $33 \mathrm{~km} / \mathrm{Myr}$ for the east side (light blue). The geomagnetic polarity model for the blue profiles is also shown. See text on the forward modeling in detail
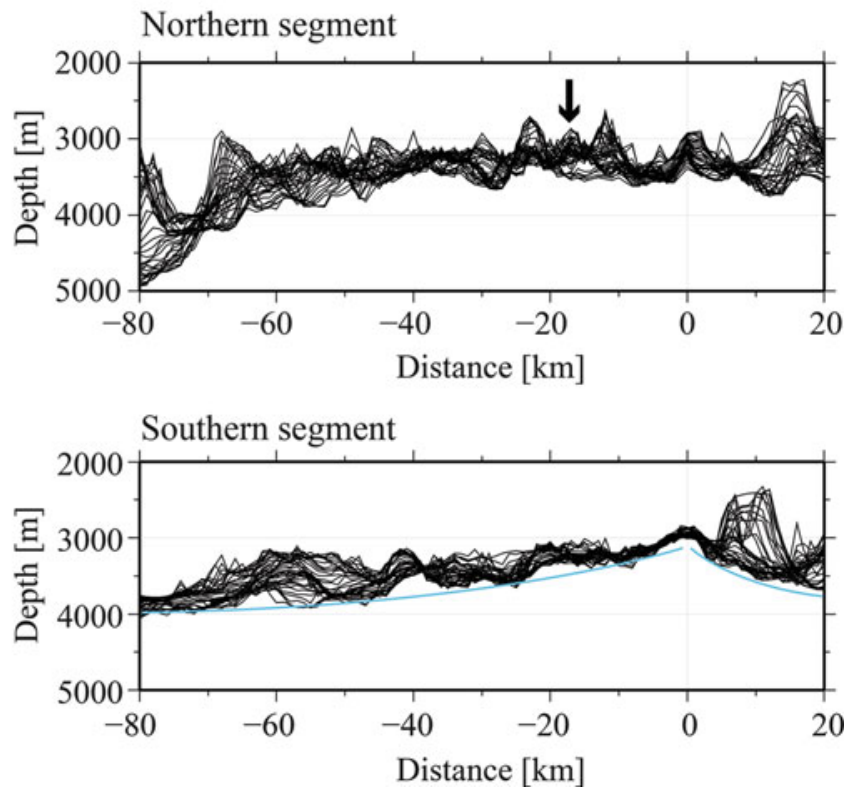

failed spreading axis. The blue lines in the southern segment bathymetry profiles show the trends of the water depth changes, which indicate high asymmetry in the seafloor deepening rate as much slower seafloor deepening rate in the west side of the spreading axis compared to the east side. In the left figure, the present spreading axis (solid lines), failed spreading axis (broken lines), and depth contours to the surface of the subducting slab (thin solid lines with their depth in $\mathrm{km}$ ) inferred from a seismic research (Gudmundsson and Sambridge 1998) are also shown

features of the Southern Mariana Trough back-arc basin show fast spreading characteristics, suggesting the abundant magma supply, even though the full spreading rate is categorized as slow spreading.

The Japanese TAIGA Project (Urabe, Chap. 1) selected the Southern Mariana Trough back-arc basin as one of three integrated target sites (Seama et al. Chap. 17), and series of JAMSTEC research cruises were conducted by the Japanese research vessel, S/V Yokosuka as well as the Shinkai 6500 submersible operations in this area. Surface geophysical surveys allow us to collect multi-narrow beam bathymetry and geomagnetic field data along with GPS navigation during YK99-11, YK09-08, YK10-10, and YK10-15 cruises, and to characterize tectonic features of the Southern Mariana Trough back-arc basin. Multi-narrow beam bathymetric data were obtained using a SeaBeam 2112 (Swath width $150^{\circ}$; 150 beams with its width and interval of $2^{\circ}$ and $1^{\circ}$, respectively). Geomagnetic field data were collected with a shiptowed proton precession magnetometer that measures the intensity of the geomagnetic field. We could cover an approximately $150 \times 150 \mathrm{~km}$ area with a nominal 4-11 km track spacing (Fig. 20.1).

In this paper, we first analyze the multi-narrow beam bathymetric data and geomagnetic field data to characterize two ridge segments of the Southern Mariana Trough back- 
arc basin. Then, we show different styles of the asymmetric seafloor spreading between the two ridge segments. Finally, we discuss a possible cause for the asymmetric seafloor spreading with relation to the subducting slab.

\subsection{Data Analysis and Result}

We compiled all the multi-narrow beam bathymetric data to be gridded at $0.1 \mathrm{~min}$ spacing using the surface algorithm of Smith and Wessel (1990) with a tension of 0.35. The prediction bathymetry data (Smith and Sandwell 1997) were also used for the outside area surveyed. Then, we traced the nontransform offsets that define the ridge segments at the offaxis using the seafloor morphology signature; ends of lineaments parallel to the spreading axis, commonly troughs, and/or isolated basins (Fig. 20.2). Two major ridge segments are recognized in the Southern Mariana Trough back-arc basin (we call the northern segment and the southern segment here after as shown in Fig. 20.3). We stacked the bathymetry profiles across the spreading axes of the two segments (Fig. 20.3). Each bathymetry profile was obtained from the gridded bathymetry data between the two red lines of each segment in Fig. 20.3, and it is taken parallel to the red lines with interval of $1 \mathrm{~km}$. The results of the bathymetry profiles show different features between the southern segment and the northern segment. The southern segment bathymetry profiles indicate that the shallowest water depth locates at the spreading axis and that the water depth increases as the distance from the spreading axis increases (blue lines in Fig. 20.3) like the age-depth profiles (Parsons and Sclater 1977) except local seamounts. But the seafloor deepening rate shows high asymmetry as much slower seafloor deepening rate in the west side of the spreading axis compared to the east side. The northern segment bathymetry profiles indicate a peak at the spreading axis, but also show symmetric with respect to a point at a distance of $18 \mathrm{~km}$ to the west from the spreading axis (arrow in Fig. 20.3). This symmetry is local within a distance of $10 \mathrm{~km}$ with respect to the point, but this local symmetry axis (the point) is similar in the bathymetric feature to a spreading axis.

Geomagnetic anomaly field was calculated by subtracting the 11th Generation International Geomagnetic Reference Field (IGRF11; Finlay et al. 2010) from the total intensity geomagnetic field data. We needed to add some values to correct biases depending on which year the data were obtained by examining the geomagnetic anomaly field data at cross over points of the ship's tracks. The biases are probably due to the imperfection of the geomagnetic reference field in the area surveyed. The geomagnetic anomaly field profiles along the ship's tracks are shown in Fig. 20.1.

The geomagnetic anomaly field was inverted for the crustal magnetization. We used the three-dimensional
Fourier inversion approach of Parker and Huestis (1974), which also takes into account the effect of bathymetry. The input grid data set was prepared as following. The geomagnetic anomaly field data were gridded at 0.4 min spacing with $256 \times 256$ points using the surface algorithm of Smith and Wessel (1990) with a tension of 0.25 . The bathymetry data were also gridded in a manner similar to geomagnetic data but with a tension of 0.35 . The magnetization solution was band-pass filtered with its passband between 5 and $80 \mathrm{~km}$ after an each iteration of the calculation to ensure convergence of the inversion solution. The main assumptions of the inversion method are; (1) the magnetization is constant with depth and varies only in the horizontal dimension, (2) the magnetization direction is fixed in the direction of the geocentric axial dipole, and (3) the source region is a magnetized layer of constant thickness $(1 \mathrm{~km}$ for this study) whose upper boundary is defined by the bathymetry (Fig. 20.2). Inversion for crustal magnetization is an inherently non-unique process. One measure of this nonuniqueness is the annihilator, which is a magnetization that produces no external magnetic field. An infinite amount of annihilator can be added or subtracted from the inversion solution without affecting the resultant magnetic field. We added the annihilator for the magnetization at the present spreading axis to be positive. The computed magnetization result is shown in Fig. 20.2.

We have identified the major isochrones with the crustal magnetization distribution using the polarity timescale of Cande and Kent (1995) (Fig. 20.2), and we examined the isochrones identifications of the southern segment using a forward modeling of the geomagnetic anomaly field. In the forward modeling, we assumed a $1 \mathrm{~km}$ thick magnetized layer with its upper depth of $3.5 \mathrm{~km}$. The magnetization of $10 \mathrm{~A} / \mathrm{m}$ is based on a square wave function constructed with the geomagnetic polarity by Cande and Kent (1995). We changed spreading rates manually to fit the synthetic geomagnetic anomaly with observed one. We applied this method to two profiles of the geomagnetic anomaly field across the spreading axis of the southern segment, which are shown by red color in Fig. 20.1. We obtained a model to reasonably fit observed ones (Fig. 20.4) and confirmed our isochrones identifications of the crustal magnetization distribution (Fig. 20.2). The model allows us to estimate the full spreading rate as $46 \mathrm{~km} / \mathrm{Myr}$ with its half rate of $33 \mathrm{~km} / \mathrm{Myr}$ for the west side and $13 \mathrm{~km} / \mathrm{Myr}$ for the east side. We did not apply this method to the northern segment, because of its specific situation; the northern segment area is near the geomagnetic equator and the strike of magnetic source is expected to be north-south, which is nearly parallel to the present spreading axis. In this situation, the total intensity of the geomagnetic anomaly has almost no signal from the magnetic source and only three-dimensional effect such as bathymetry helps to derive the signal. Thus, the crustal 
magnetization distribution calculated by the threedimensional inversion approach is an only way to identify the geomagnetic anomaly for the northern segment.

\subsection{Discussions}

Our estimation of the spreading rates based on the geomagnetic anomaly field data shows highly asymmetric seafloor spreading of the southern segment; much faster spreading in the west side of the spreading axis compared to the east side (Fig. 20.4). The bathymetry profiles across the spreading axis of the southern segment also support this highly asymmetric seafloor spreading; the seafloor deepening rate from the spreading axis show high asymmetry as much slower seafloor deepening rate in the west side of the spreading axis compared to the east side (blue lines in Fig. 20.3). We estimated the full spreading rate of $46 \mathrm{~km} / \mathrm{Myr}$ with its half rate of $33 \mathrm{~km} / \mathrm{Myr}$ for the west side and $13 \mathrm{~km} / \mathrm{Myr}$ for the east side, which are based on the crustal magnetization distribution and the forward modeling of the geomagnetic anomaly field. These half spreading rates are also supported by the bathymetry profiles of the spreading axis (Fig. 20.3), because the water depths at both the sides of the spreading axis become the same when the crustal ages inferred from these half spreading rates are the same; both the water depths are about $3,500 \mathrm{~m}$ at $1 \mathrm{Ma}$ crustal age with the distance of $33 \mathrm{~km}$ to the west and of $13 \mathrm{~km}$ to the east side from the spreading axis. Further, the full rate of $46 \mathrm{~km} / \mathrm{Myr}$ is consistent with the present full spreading rate of $44.6 \pm 2.7 \mathrm{~km} /$ Myr at $13.6^{\circ} \mathrm{N}$ based on the repeated GPS surveys (Kato et al. 2003), although the full spreading rate from the geomagnetic anomaly field data is not necessary to be congruent with the present full spreading rate, because it is an average of the full spreading rate for the time scale of the geomagnetic polarity change.

The northern segment shows different features in contrast to the southern segment, and we propose that the northern segment of the spreading axis has a different style of the asymmetric seafloor spreading; that is accompanied by an obvious trace of a ridge jump to the east (trench side). The obvious trace of the ridge jump is supported by the bathymetry profiles across the spreading axis (Fig. 20.3), the Mantle Bouguer anomalies (MBA) based on Kitada et al. (2006), and the distribution of the crustal magnetization derived from the total intensity of the geomagnetic anomaly field data (Fig. 20.2). A local symmetry axis in the bathymetry profiles, which locates at distance of $18 \mathrm{~km}$ to the west from the spreading axis, is probably the failed spreading axis due to the ridge jump because the local symmetry axis is similar in the bathymetric feature to a spreading axis. This failed spreading axis is also supported by the MBA because its location coincides with the center of the bull's eye feature in the MBA (arrow in Fig. 20.2), which is often found at ridge segments of slow spreading axes (e.g. Lin et al. 1990). The fact that the bull's eye feature still remains suggests that the ridge jump occurred recently. The crustal magnetization distribution also supports the ridge jump, because the ridge jump can explain the existence of the negative magnetization lineation between the present spreading axis and the failed spreading axis. We interpret that the negative magnetization lineation is Matuyama Chron (before $0.78 \mathrm{Ma}$ ) made by the failed spreading axis in its east side and that the ridge jump occurred during the Brunhes Chron (after 0.78 Ma). If the negative magnetization lineation would be made by the present spreading axis without the ridge jump, the half spreading rate would be $5 \mathrm{~km} / \mathrm{Myr}$ in maximum (the distance from the present spreading axis to the MatuyamaBrunhes boundary is $4 \mathrm{~km}$ in maximum), which is too slow spreading rate to be consistent with other data. Our interpretation that the ridge jump occurred during the Brunhes Chron is consistent with the recent ridge jump suggested by the fact that the bull's eye feature still remains. The ridge jump results in the apparent asymmetric seafloor spreading of the northern segment. We have calculated the average half spreading rate for the west side of the north segment and it becomes $27 \mathrm{~km} / \mathrm{Myr}$ using the distance of $48 \mathrm{~km}$ from the present spreading axis to the geomagnetic anomaly isochron 2 (Fig. 20.2). This apparent half spreading rate that includes the ridge jump is slightly slower than $33 \mathrm{~km} / \mathrm{Myr}$, the half spreading rate for the west side of the southern segments, but it still shows the apparent asymmetric seafloor spreading if the full spreading rate is $46 \mathrm{~km} / \mathrm{Myr}$. It is difficult to estimate the half spreading rate for the east side because some seamounts probably due to the arc volcanism reset and/or mask the original seafloor magnetization as suggested by the positive magnetization distribution with shallow water depth (Fig. 20.2).

Both of the northern and the southern segments show highly asymmetric seafloor spreading, but their styles are different; the northern segment of the spreading axis is accompanied by the obvious trace of the ridge jump to the east (trench side), while the southern segment is not. As a characteristic feature in the northern segment, the seafloor spreading shows a difference between the present spreading axis and the failed spreading axis; the present spreading axis shows fast spreading morphologic and geophysical characteristics (Martinez et al. 2000; Kitada et al. 2006; Becker et al. 2010), but the failed spreading axis shows slow spreading geophysical characteristics of the bull's eye feature in the MBA. Since the full spreading rate of $46 \mathrm{~km} /$ Myr is categorized as slow spreading, the failed spreading axis is normal and the present spreading axis should receive the additional magma supply, suggesting that the ridge jump to the trench side with an increase in the magma supply. In contrast, the southern segment shows the asymmetric 
seafloor spreading without accompanied by an obvious trace of a ridge jump. Two possible mechanisms for the southern segment are; (1) series of much smaller ridge jumps than that of the northern segment without presenting their obvious traces and/or (2) the asymmetric manner of the crustal accretion itself. The bathymetry profiles (Fig. 20.3) might support the series of small ridge jumps without presenting their obvious traces because the seafloor deepening rate in the west side of the spreading axis does not seem to be constant, but we think further evidence is required to support this.

We propose that an influence of the low viscosity region in the mantle wedge leads the highly asymmetric seafloor spreading, and that the different styles of the asymmetric seafloor spreading show evidence that the influence varies with the distance from the low viscosity region. Several authors suggested the low viscosity mantle in the mantle wedge due to hydration driven by water release from the subducting slab (e.g. Dunn and Martinez 2011). The dehydration from the subducting slab at the depths of $110 \mathrm{~km}$ and $170 \mathrm{~km}$ leads to arc volcanic chains in subduction zone (e.g. Tatsumi and Eggins 1995), and it also leads to the low viscosity region in the mantle wedge with low yield strength due to effect of water and melt generation for the arc volcanic chains. Since the spreading axis can always be located at the weak arc area with the low viscosity and yield strength in the mantle wedge as suggested by numerical simulation results (Nakakuki and Mura 2013), we suggested that the low viscosity mantle preferentially captures the mantle upwelling zone beneath the spreading axis, which would lead to the highly asymmetric seafloor spreading; the spreading axis has been kept in the area closed to the low viscosity region in the mantle wedge. The influence of the low viscosity region probably varies with the distance from the low viscosity region as Martinez and Taylor (2002) proposed that the spreading center varies with the distance from the arc volcanic front. Although the present arc volcanic chains of the Southern Mariana Trough back-arc basin are not clear and the low viscosity region has not been imaged, the depths to the surface of the subducting slab (we call the slab depth here after) is a suitable indicator for the arc volcanic chains and the low viscosity region, because the slab depth beneath arc volcanic chains in subduction zone is expected to be 110-170 km (e.g. Tatsumi and Eggins 1995). The shape of the subducting slab beneath the Southern Mariana Trough back-arc basin inferred from a seismic research (Gudmundsson and Sambridge 1998), indicates that the subducting slab is oblique to the spreading axis (Fig. 20.3) up to $14.5^{\circ} \mathrm{N}$ where it is divided by a near-vertical tear in the slab striking approximately E-W (Miller et al. 2006). The slab depth beneath the spreading axis becomes shallower from the north to the south; 160-190 km depth for the northern segment and 120-150 km depth for the southern segment. The morphology of the spreading axis shows narrow cross section of the axial relief in the northern segment while broader cross section in the southern segment (Fig. 20.1), indicating an increase in the magma supply as the slab depth becomes shallower from the north to the south. Furthermore, the ridge jump in the northern segment to the trench side, closer to the mantle wedge, results in the increase in the magma supply as its characteristic features change from the bull's eye feature in the MBA to the axial relief morphology. The failed spreading axis locates above the relatively deeper slab depth and is probably away from the low viscosity region. This ridge jump closer to the mantle wedge with the increase in the magma supply suggests that the mantle upwelling zone that is captured by the low viscosity region in the mantle wedge leads to the ridge jump. In contrast, the spreading axis of the southern segment is closer to the mantle wedge and is probably underlain by the low viscosity region, because the slab depth beneath the spreading axis is $120-150 \mathrm{~km}$ that is where the arc volcanic chains are expected to be located. Then, the mantle upwelling zone captured by the low viscosity region probably provides the additional magma to support the broader axial relief, and results in the asymmetric seafloor spreading without accompanies by an obvious trace of a ridge jump. Thus, the different styles of the asymmetric seafloor spreading between the northern segment and the southern segment probably show evidence that the influence varies with the slab depth, which is well related to the distance from the low viscosity region. The transition between the northern segment and the southern segment is not abrupt as suggested at the Lau back-arc basin (Dunn and Martinez 2011), possible because the shape and the size of the low viscosity region of the Southern Mariana Trough back-arc basin are different from those of the Lau back-arc basin due to the differences in the spreading rate and the obliqueness of the subducting slab to the spreading axis. The Southern Mariana Trough back-arc basin shows the slower spreading rate and higher obliqueness of the subducting slab compared to the Lau back-arc basin.

\subsection{Conclusion}

Our analysis based on the bathymetry, the geomagnetic anomaly field, and the Mantle Bouguer anomaly, suggests highly asymmetric seafloor spreading in the Southern Mariana Trough back-arc basin; much faster spreading in the west side of the spreading axis compared to the east side (trench side). But the style of asymmetric seafloor spreading is different between the northern segment and the southern segment; the northern segment is accompanied by the obvious trace of the ridge jump to the trench side with the increase in the magma supply, while the southern segment 
is not. We propose that the influence of the low viscosity region in the mantle wedge due to hydration driven by water release from the subducting slab leads to the highly asymmetric seafloor spreading; the low viscosity mantle would preferentially captures the mantle upwelling zone beneath the spreading axis as the spreading axis has been kept nearly in the area expected to the arc volcanic chains and closed to the low viscosity region, resulting in the highly asymmetric seafloor spreading. Further, the different styles of the asymmetric seafloor spreading between the northern segment and the southern segment probably show evidence that the influence varies with the slab depth, which is well related to the distance from the low viscosity region in the mantle wedge.

Acknowledgments We thank all who assisted in the collection of the geophysical data during the YK99-11, YK09-08, YK10-10, and YK1015 JAMSTEC (Japan Agency for Marine-Earth Science and Technology) research cruises by the Japanese research vessel, S/V Yokosuka. This work is supported by the Ministry of Education, Culture, Sports, Science and Technology (MEXT) of Japan for the TAIGA project, Grant-in-Aid for Scientific Research on Innovative Areas (20109002). Two anonymous reviewers provided helpful comments. Kumiko Okumura drew some figures and helped to prepare the manuscript. GMT software (Wessel and Smith 1998) was used to create the bathymetry map of the survey area.

Open Access This chapter is distributed under the terms of the Creative Commons Attribution Noncommercial License, which permits any noncommercial use, distribution, and reproduction in any medium, provided the original author(s) and source are credited.

\section{References}

Becker NC, Fryer P, Moore GF (2010) Malaguana-Gadao Ridge: identification and implications of a magma chamber reflector in the southern Mariana Trough. Geochem Geophys Geosyst 11: Q04X13. doi:10.1029/2009GC002719

Cande SC, Kent DV (1995) Revised calibration of the geomagnetic polarity timescale for the late Cretaceous and Cenozoic. J Geophys Res 100:6093-6095

Dunn RA, Martinez F (2011) Contrasting crustal production and rapid mantle transitions beneath back-arc ridges. Nature 469:198-202
Finlay CC, Maus S, Beggan CD, Hamoudi M, Lowes FJ, Olsen N, Thébault E (2010) Evaluation of candidate geomagnetic field models for IGRF-11. Earth Planets Space 62(10):787-804. doi:10. 5047/eps.2010.11.005

Gudmundsson O, Sambridge M (1998) A regionalized upper mantle (RUM) seismic model. J Geophys Res 103(B4):7121-7136

Kato T, Beavan J, Matsushima T, Kotake Y, Camacho JT, Nakao S (2003) Geodetic evidence of back-arc spreading in the Mariana Trough. Geophys Res Lett 30(12):1625. doi:10.1029/ 2002GL016757

Kitada K, Seama N, Yamazaki T, Nogi Y, Suyehiro K (2006) Distinct regional differences in crustal thickness along the axis of the Mariana Trough, inferred from gravity anomalies. Geochem Geophys Geosyst 7, Q04011. doi:10.1029/2005GC001119

Lin J, Purdy GM, Schouten H, Sempéré J-C, Zervas C (1990) Evidence from gravity data for focused magmatic accretion along the MidAtlantic Ridge. Nature 344:627-632

Martinez F, Fryer P, Becker N (2000) Geophysical characteristics of the southern Mariana Trough, $11^{\circ} 50^{\prime} \mathrm{N}-13^{\circ} 40^{\prime} \mathrm{N}$. J Geophys Res 105:16591-16607

Martinez F, Taylor B (2002) Mantle wedge control onback-arc crustal accretion. Nature 416:417-420

Miller MS, Gorbatov A, Kennett BLN (2006) Three-dimensional visualization of a near-vertical slab tear beneath the southern Mariana arc. Geochem Geophys Geosyst 7:Q06012. doi:10.1029/ 2005GC001110

Nakakuki T, Mura E (2013) Dynamics of slab rollback and induced back-arc basin formation. Earth Planet Sci Lett 361:287-297. doi:10.1016/j.epsl.2012.10.031

Parker RL, Huestis SP (1974) The inversion of magnetic anomalies in the presence of topography. J Geophys Res 79:1587-1593

Parsons B, Sclater JG (1977) An analysis of the variation of ocean floor bathymetry and heat flow with age. J Geophys Res 82:803-827. doi:10.1029/JB082i005p00803

Smith WHF, Wessel P (1990) Gridding with continuous curvature splines in tension. Geophysics 55(3):293-305

Smith WHF, Sandwell DT (1997) Global seafloor topography from satellite altimetry and ship depth soundings. Science 277:1956-1962

Tatsumi Y, Eggins S (1995) Subduction zone magmatism. Blackwell, Boston

Wessel P, Smith WHF (1998) New, improved version of the Generic Mapping Tools released. EOS Trans Am Geophys Un 79:579

Yamazaki T, Seama N, Okino K, Kitada K, Joshima M, Oda H, Naka J (2003) Spreading process of the northern Mariana Trough: riftingspreading transition at $22^{\circ} \mathrm{N}$. Geochem Geophys Geosyst 4(9): 1075 . doi: $10.1029 / 2002 \mathrm{GC} 000492$ 